\title{
Secondary Metabolites with Anti-complementary Activity from the Stem Barks of Juglans mandshurica Maxim ${ }^{1}$
}

\author{
Zi-Jiang $\mathrm{Li}^{2,3} \cdot$ Shilin Chen ${ }^{2} \cdot$ Xiang-Hao Yang ${ }^{2} \cdot$ Rui Wang ${ }^{2} \cdot$ Hee-Jeong Min ${ }^{4} \cdot$ \\ Lei $\mathrm{Wu}^{5} \cdot$ Chuan-Ling $\mathrm{Si}$ (D) $^{2,4,5} \cdot$ Young-Soo Bae (D) ${ }^{4,5, \dagger}$
}

\begin{abstract}
Juglans mandshurica is a fast growing hard species, which is a tree in family of Juglandaceae and has a wide distribution in China, Korea and eastern Russia. Plant materials from J. mandshurica have extensively been used in folk medicines to prevent or cure gastric, esophageal, lung and cardiac cancer. As one chain of our searching for anticomplementary agents from natural sources, two epimeric ellagitannins, [2,3-O-4,4',5,5',6,6',-hexahydroxydiphenoyl (HHDP))-( $\alpha, \beta$ )-D-glucose] (I) and pedunculagin (II) were purified from 70\% acetone extracts of the stem barks of J. mandshurica by Thin Layer Chromatography and Sephadex LH-20 column chromatography approaches. The chemical structures of the isolated compounds were characterized by MS, NMR, and a careful comparation with published literatures. The epimeric ellagitannins I and II exhibited inhibitory properties against a classical pathway of complementary system with $50 \%$ inhibitory concentrations $\left(\mathrm{IC}_{50}\right)$ values of 65.3 and $47.7 \mu \mathrm{M}$, respectively, comparing with riliroside $\left(\mathrm{IC}_{50}=104 \mu \mathrm{M}\right)$ and rosmarinic acid $\left(\mathrm{IC}_{50}=182 \mu \mathrm{M}\right)$, which were used as positive controls. Thus, the work indicated both the two secondary metabolites possess excellent inhibitory activity and might be developed as potential anticomplementary chemicals.
\end{abstract}

Keywords: anticomplementary activity, epimeric ellagitannins, Juglans mandshurica Maxim., spectroscopic technique, secondary metabolites

\section{INTRODUCTION}

The human complement system plays an important role in the host defense system against foreign invasive organisms such as viruses, bacteria, and fungi, as well as an external wound. Its effects are normally beneficial to the host, but it can also cause adverse effects depending on the site, extent, and duration of complement activation (Cimanga et al., 1995). Activation of the system may lead to pathologic reactions in a variety of inflammatory and degenerative diseases such as multiple sclerosis, systemic lupus erythematosus, sjogren

${ }^{1}$ Date Received November 8, 2017, Date Accepted December 22, 2017

2 Tianjin Key Laboratory of Pulp \& Paper, College of Papermaking Science \& Technology, Tianjin University of Science \& Technology, Tianjin 300457, China

${ }^{3}$ Shandong Institute of Commerce and Technology, Jinan 250103, China

${ }^{4}$ Department of Forest Biomaterials Engineering, College of Forest \& Environment Sciences, Kangwon National University, Chuncheon 24341, Korea

${ }^{5}$ Institute of Applied Chemistry, Jiangxi Academy of Sciences, Nanchang 330096, China

$\dagger$ Corresponding author: Young-Soo Bae (e-mail: bae@kangwon.ac.kr, ORCID: 0000-0003-1108-9269)

$\dagger$ Corresponding author: Chuan-Ling Si (e-mail: sichli@tust.edu.cn, ORCID: 0000-0003-1630-7800) 
syndrome, dermatological disease, rheumatoid arthritis, and gout. Therefore, the modulation of complement activity is important and there is a need to develop anti-complementary agents from various sources such as plants (Park et al., 1999; Min et al., 2003).

Juglans mandshurica Maxim (Juglandaceae), a fast growing deciduous tree, is widely distributed in China, Siberia and Korean peninsula. The tree has been used as a folk medicinal plant for the treatment of esophageal, gastric, cardiac and lung cancer. It was reported that volatile constituents from the species inhibited the growth of the neighboring plants and can be developed for chemurgy (Min et al., 2003; Kim, 1994). Some of the valuable constituents such as $\alpha$-tertalonyl glucopyranosides, naphthoquinones, naphthalenyl glycosides, flavonoids, galloyl glucopyranosides and diarylheptanoyl glucopyranosides have already been isolated from this species (Park et al., 2017; Wang et al., 2017; Min et al., 2003; Li et al., 2003). In addition, several studies have reported the anti-complement activity, inhibition of human immunodeficiency virus type 1 reverse transcriptase and ribonuclease $\mathrm{H}$ activities of $J$. mandshurica extract (Bi et al., 2016; Min et al., 2003; Min et al., 2000).

Thus, and as a part of a project aimed at discovering bioactive and structurally novel compounds from plant sources, the chemical constituents of $J$. mandshurica bark and their anti-complement activity were investigated.

\section{MATERIALS and METHODS}

\subsection{Instruments}

Melting points (uncorrected) were determined with an Electro Thermal 9100 apparatus. Optical rotations were measured on a JASCO DIP-1000 digital polarimeter in $\mathrm{MeOH}$. IR spectra were obtained on a Perkin-Elmer BX FT-IR spectrometer in a $\mathrm{KBr}$ disk. UV spectra were recorded in $\mathrm{MeOH}$ (Jenway 6405 spectrophotometer). ${ }^{1} \mathrm{H}-\mathrm{NMR}(400 \mathrm{MHz})$ and ${ }^{13} \mathrm{C}-\mathrm{NMR}(100 \mathrm{MHz})$ spectra were recorded in $\mathrm{MeOH}-d_{4}$ with TMS (Tetramethylsilane) as an internal standard using a Bruker Avance DPX 400 spectrometer. MALDI- TOF-MS spectroscopy was measured on a Model Voyager-DE STR spectrometer.

Paper TLC analysis were carried out on DCPlastikfolien Cellulose $\mathrm{F}$ (Merck Co.) plates and developed with $t$-BuOH-HOAc- $\mathrm{H}_{2} \mathrm{O}(3: 1: 1, \mathrm{v} / \mathrm{v} / \mathrm{v}$, solvent A) and $\mathrm{HOAc}-\mathrm{H}_{2} \mathrm{O}(3: 47, \mathrm{v} / \mathrm{v}$, solvent B). TLC spots were detected by UV-light (254 and 365 $\mathrm{nm}$ ) and by spraying with $1 \% \mathrm{FeCl}_{3}$ (in $\mathrm{EtOH}$ ) solution followed by heating.

\subsection{Anti-complement Assay}

Anti-complement properties of the isolated epimeric ellagitannins were evaluated by a method adopted from Yamada et al.(1985). A diluted solution of normal human serum (complement serum, $80 \mu \mathrm{L}$ ) was mixed with a gelatin veronal buffer $\left(\mathrm{GVB}^{2+}, 80 \mu \mathrm{L}\right)$ without or with samples. The mixture was pre-incubated at $37^{\circ} \mathrm{C}$ for $30 \mathrm{~min}$, followed by adding sensitized erythrocyte (sheep red blood cells, $40 \mu \mathrm{L}$ ). After incubation under the same conditions, the mixture was centrifuged $\left(4^{\circ} \mathrm{C}\right.$, $1500 \mathrm{rpm})$ and the absorbance of the supernatant (100 $\mu \mathrm{L}$ ) was measured at $450 \mathrm{~nm}$ by a UV spectrometer (Libra S32, Biochrom). Each sample was dissolved in DMSO as negative control, while tiliroside and rosmarinic acid were used as positive controls. Anti- complement activity was determined as a mean of three independent trials and expressed as the $50 \%$ inhibitory concentration $\left(\mathrm{IC}_{50}\right)$ values from complement- dependent hemolysis of the control (Jung et al., 1998; Oh et al., 2000).

\subsection{Plant Material}

The stem bark was stripped from a 10 -year-old $J$. mandshurica tree grown in the experimental forest of 
Zi-Jiang Li $\cdot$ Shilin Chen $\cdot$ Xiang-Hao Yang $\cdot$ Rui Wang $\cdot$ Hee-Jeong Min $\cdot$ Lei Wu $\cdot$ Chuan-Ling Si $\cdot$ Young-Soo Bae

Kangwon National University, Korea in April, 2005 and was identified by Prof. Wan-Keun Park, School of Forest, Kangwon National University, Korea. A voucher specimen has been deposited at the herbarium of Laboratory of Natural Products, Kangwon National University, Korea.

\subsection{Extraction and Fractionation}

The bark of $J$. mandshurica was air-dried and ground with a Wiley mill. A precisely weighted amount (3.2 $\mathrm{kg}$ ) was extracted in $70 \%$ acetone aqueous solution (each $20 \mathrm{~L}$ for $72 \mathrm{~h} \times 3$ times) at room temperature. The extracting solutions were filtered, combined, and concentrated with an evaporator under reduced pressure to afford the crude extract, which was suspended in water and then successively submitted to liquid-liquid fractions with in separation funnels using $n$-hexane, methylene chloride $\left(\mathrm{CH}_{2} \mathrm{Cl}_{2}\right)$, ethylacetate (EtOAc) and $n$-buthanol (n-BuOH) (Si et al., 2017). For the detailed extraction and fractionation procedures see Fig. 1. The soluble fractions in $n$-hexane (15.6 g, yield $0.5 \%)$, $\mathrm{CH}_{2} \mathrm{Cl}_{2}$ (20.6 g, yield 0.6\%), EtOAc (130 g, yield 4.1\%) and $\mathrm{H}_{2} \mathrm{O}(337.6 \mathrm{~g}$, yield $10.6 \%$ ) were obtained after freezing-drying as powders.

\subsection{Isolation of Ellagitannins}

As shown in Fig. 1, a portion of the resulting $\mathrm{H}_{2} \mathrm{O}$ soluble Fr. (40.0 g) was applied to a Sephadex LH-20 column eluting with $\mathrm{MeOH}-\mathrm{H}_{2} \mathrm{O}(1: 1, \mathrm{v} / \mathrm{v})$ to give four fractions: $\mathrm{H}_{1}(12.4 \mathrm{~g}), \mathrm{H}_{2}(8.5 \mathrm{~g}), \mathrm{H}_{3}(16.2 \mathrm{~g})$ and $\mathrm{H}_{4}$ $(2.8 \mathrm{~g})$, which were sampled and their composition were monitored by Paper TLC. Fraction $\mathrm{H}_{3}$ was reapplied to a Sephadex LH-20 column using EtOH-hexane (3 : 1, $\mathrm{v} / \mathrm{v}$ ) as eluent for further purification to yield three subfractions and the third subfraction $\mathrm{H}_{33}(8.9 \mathrm{~g})$ was stepwisely rechromatographed with $\mathrm{MeOH}-\mathrm{H}_{2} \mathrm{O}(1: 3, \mathrm{v} / \mathrm{v})$ to give subfractions $\mathrm{H}_{331}(1.8 \mathrm{~g})$ and $\mathrm{H}_{332}(6.2 \mathrm{~g})$ and compound

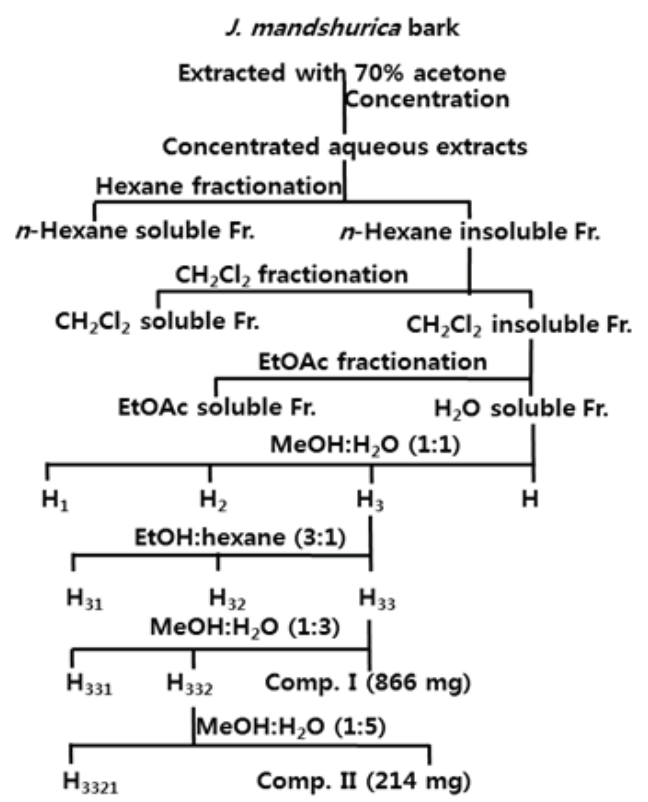

Fig. 1. Extraction, fractionation and isolation procedures of tannins from $J$. mandshurica stem bark.

I (866 mg). Subfraction $\mathrm{H}_{332}$ was resubjected to a Sephadex LH-20 column and eluted with $\mathrm{MeOH}-\mathrm{H}_{2} \mathrm{O}$ $(1: 5, \mathrm{v} / \mathrm{v})$ for further separation to give subfraction $\mathrm{H}_{3321}(5.9 \mathrm{~g})$ and compounds II $(214 \mathrm{mg})$.

\section{RESULTS and DISCUSSION}

Compound I, which has never been reported from $J$. mandshurica previously, was isolated as a colorless amorphous powder with melting point of $112-114{ }^{\circ} \mathrm{C}$ and optical rotation of $[\alpha]_{\mathrm{D}}^{20}+18.5^{\circ}(c 0.1$ in $\mathrm{MeOH})$. On paper TLC, its $\mathrm{R}_{f}$ (Retention Factor) values are 0.68 (solvent A) and 0.77 (solvent B). Its molecular weight 482 and molecular formula $\mathrm{C}_{20} \mathrm{H}_{18} \mathrm{O}_{14}$ was determined based on the quasi-molecular ion peaks $m / z[\mathrm{M}+\mathrm{Na}]^{+}$ at $505,[\mathrm{M}+\mathrm{K}]^{+}$at $521,[2 \mathrm{M}+\mathrm{Na}]^{+}$at 987 and $[2 \mathrm{M}+\mathrm{K}]^{+}$ at 1003 in the MALDI-TOF-MS spectrum. The presence of phenolic hydroxyl group in the molecule was recognized from grey-green color with ethanolic $\mathrm{FeCl}_{3}$ 
solution on TLC(Imakura et al, 1985). In its IR spectrum, absorption bands at 3380, 1738, 1615, 1511, $1435,1230,1185,875,830,735\left(\mathrm{~cm}^{-1}\right.$ in $\left.\mathrm{KBr}\right)$ were observed. Its UV spectrum showed maxima at $262 \mathrm{~nm}$ (in $\mathrm{MeOH}$ ). In ${ }^{1} \mathrm{H}$ - and ${ }^{13} \mathrm{C}-\mathrm{NMR}$ spectra, A characteristic anomeric mixture of $\alpha$ - and $\beta$-D-glucose and connecting 4,4',5,5',6,6',-hexahydroxydiphenoyl (HHDP) residues were observed. However, compound I, a pair of epimers, could not be completely separated by column chromatography though it appeared as only one spot on two-dimensional paper TLC. Its spectroscopic data were identical with those reported by Seikel et al(1970), thus compound I was identified as 2,3-O-4, $4^{\prime}, 5,5^{\prime}, 6,6^{\prime}$-HHDP- $(\alpha \beta)$-D-glucose.

Compound II was obtained as a pale brown amorphous powder for the first time from this species. The melting point was $135-137^{\circ} \mathrm{C}$. We found its optical rotation $[\alpha]_{\mathrm{D}}^{20}$ of $+106^{\circ}$ (c 0.1 in $\left.\mathrm{MeOH}\right)$. Its IR and UV absorption bands were similar with those of compound I described above. $\mathrm{R}_{f}$ of this compound are 0.29 (solvent A) and 0.55 (solvent B). The MALDITOF-MS spectrum of compound II gave peaks of $\mathrm{m} / \mathrm{z}$ $[\mathrm{M}+\mathrm{Na}]^{+}$at $807,[2 \mathrm{M}+\mathrm{K}]^{+}$at $823,[2 \mathrm{M}+\mathrm{Na}]^{+}$at 1591 , $[2 \mathrm{M}+\mathrm{K}]^{+}$at 1607 , respectively, corresponding to the molecular formula $\mathrm{C}_{20} \mathrm{H}_{18} \mathrm{O}_{14}$. Similar to that of compound I, compound II was also an epimeric compound, which was existing in equilibrium as anomeic mixture of $\alpha$ - and $\beta$-D-glucoses as described in previously published literatures (Tsujita et al., 2017; Seikel et al., 1970). In the ${ }^{1} \mathrm{H}-\mathrm{NMR}$ spectrum of compound II, two sets of partially overlapped $\alpha$ - and $\beta$-D-glucose were confirmed. In addition, four sets of 4,4 '5,5',6,6',-hexahydroxydiphenoyl (HHDP) moieties were observed. The ${ }^{13} \mathrm{C}-\mathrm{NMR}$ of compound II also presented duplicated signals due to the presence of a pair of epimers. These ${ }^{1} \mathrm{H}$ - and ${ }^{13} \mathrm{C}$-NMR data were coincided with those reported in literature (Seikel et al., 1970) and compound II was elucidated as pedunculagin consequently.

\subsection{2,3-O-4, $4^{\prime}, 5,5^{\prime}, 6,6^{\prime}-\mathrm{HHDP}-(\alpha / \beta)-$ D-Glucose (I)}

Colorless amorphous powder; mp $112-114{ }^{\circ} \mathrm{C} ;[\alpha]_{\mathrm{D}}^{20}$ $+18.5^{\circ}$ (c 0.1 in $\mathrm{MeOH}$ ); IR (KBr) Vmax $\mathrm{cm}^{-1} 3380$, $1738,1615,1511,1435,1230,1185,875,830,735$; UV $\lambda \max (\mathrm{MeOH}) \mathrm{nm} 262 ; \mathrm{R}_{f}: 0.68$ (solvent A) and 0.77 (solvent B); MALDI-TOF-MS : $\mathrm{m} / \mathrm{z}[\mathrm{M}+\mathrm{Na}]^{+}$ at $505,[\mathrm{M}+\mathrm{K}]^{+}$at $521,[2 \mathrm{M}+\mathrm{Na}]^{+}$at 987 and $[2 \mathrm{M}+\mathrm{K}]^{+}$ at $1003 ;{ }^{1} \mathrm{H}$ - and ${ }^{13} \mathrm{C}-\mathrm{NMR}$ data were identical with those in the literature (Seikel et al., 1970).

\subsection{Pedunculagin (II)}

Pale brown amorphous powder; mp $135-137^{\circ} \mathrm{C} ;[\alpha]_{\mathrm{D}}^{20}$ $+106^{\circ}$ (c 0.1 in $\left.\mathrm{MeOH}\right)$; IR (KBr) $\nu_{\max } \mathrm{cm}^{-1} 3380$,
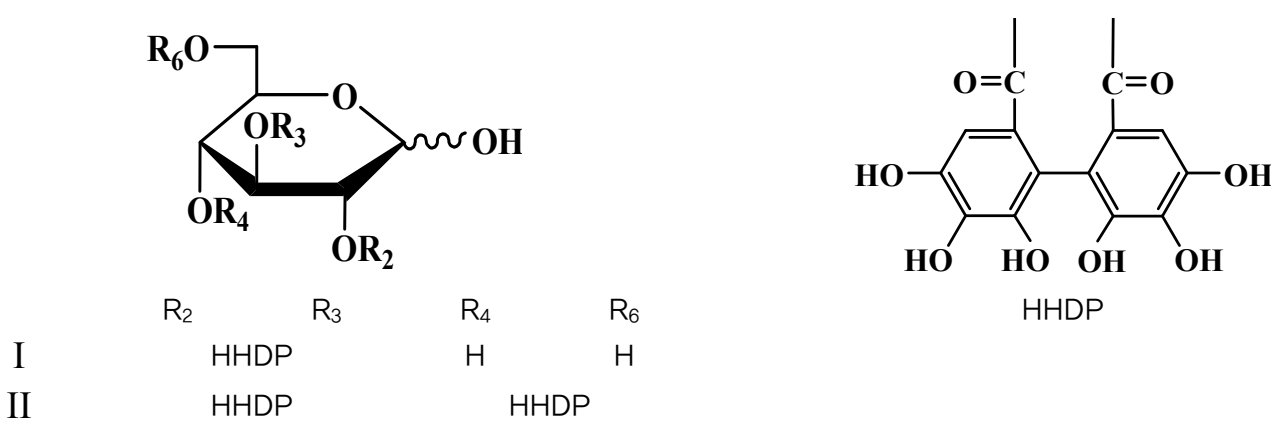

Fig. 2. Structures of isolated epimeric ellagitannins from J. mandshurica stem bark. 
Table 1. Anti-complementary effects of isolated epimeric ellagitannins by complementary system of classical pathway in vitro.

\begin{tabular}{|c|c|c|}
\hline & Sample & $\mathrm{IC}_{50}(\mu \mathrm{M})^{\mathrm{a}}$ \\
\hline \multirow{2}{*}{ Ellagi-tannins } & 2,3-O-4,4',5,5',6,6'-HHDP-( $\alpha / \beta)$-D-glucose (I) & 65.3 \\
\hline & pedunculagin (II) & 47.7 \\
\hline \multirow{2}{*}{ Positive controls } & Tiliroside & 104 \\
\hline & Rosmarinic acid & 182 \\
\hline
\end{tabular}

${ }^{a}$ Data were expressed as the mean of three independent replicates.

$1747,1615,1511,1435,1230,1185,875,830,735$; UV $\lambda_{\max }(\mathrm{MeOH}) \mathrm{nm} 260 ; \mathrm{R}_{f}: 0.29$ (solvent A) and 0.55 (solvent B); MALDI-TOF-MS : $m / z[\mathrm{M}+\mathrm{Na}]^{+} 807$, $[2 \mathrm{M}+\mathrm{K}]^{+} 823,[2 \mathrm{M}+\mathrm{Na}]^{+} 1591,[2 \mathrm{M}+\mathrm{K}]^{+} 1607 ;{ }^{1} \mathrm{H}-$ and ${ }^{13} \mathrm{C}-\mathrm{NMR}$ data were in agreement with those of the literature (Tanaka et al., 1993).

\subsection{Anti-complementary Activity}

Compounds I and II isolated from J. mandshurica stem bark were assayed for their anti-complement activity on the complement system of classical pathway (CP) in vitro and the results were summarized in Table 1. Both the two epimeric ellagitannins exhibited strong anti-complement activity with $\mathrm{IC}_{50}$ values were 65.3 and $47.7 \mu \mathrm{M}$, respectively, comparing tiliroside and rosmarinic acid 104 and $182 \mu \mathrm{M}$, respectively, which were used as positive controls. These facts suggested that the two epimeric ellagitannins could be used as anti-complement agents.

\section{CONCLUSION}

By successive liquid-liquid fractionation and repeated TLC-monitored purification of $70 \%$ aqueous acetone extraction of the $J$. mandshurica barks, two ellagitannins were isolated and their chemical structures (Fig. 2) were elucidated as 2,3-O-4,4',5,5',6,6'-HHDP-( $\alpha / \beta)$-D-glucose (I) and pedunculagin (II) based on their chemical and spectroscopic evidences, and a careful comparison with previously published data. Compounds I and II were epimeric ellagitannins and they were isolated as anomeric mixtures of $\alpha$ - and $\beta$-D-glucoses in the current work as described in literatures. It is noteworthy that this is the first report of compounds I and II from $J$. mandshurica.

The activity of the two epimeric ellagitannins (I and II) were evaluated by a classical pathway of complementary system assay, and our investigation results indicated that both the two compounds inhibited excellent effects and could be used as potential anticomplementary agents.

\section{ACKNOWLEDGMENT}

This work was kindly supported by National Key Research and Development Program of China (Grant No.2017YFB0307903), Foundation of Key Project of Research and Development Program of Jiangxi Province (No. 20171BBH80017 and 20171ACF60009), the Science and Technology Major Project Foundation of Jiangxi Academy of Sciences (2018-YZD1-05 and 2018-YZD2-18), Science Foundation for Young Doctors of Jiangxi Academy of Science (2016- YYB-07), and Introduction of Overseas Technical and Managerial Personnel Program of State Administration of Foreign Experts Affairs (20173600003), P.R. China. 
Secondary Metabolites with Anti-complementary Activity from the Stem Barks of Juglans mandshurica Maxim

\section{REFERENCES}

Bi, D.D., Zhao, Y.C., Jiang, R., Wang, Y., Tian, Y.X., Chen, X.Y., Bai, S.J., She, G.M. 2016. Phytochemistry, bioactivity and potential impact on health of Juglans: the original plant of walnut. Natural Product Communications 11(6): 869-880.

Cimanga, K., Bruyne, T.D., Lasure, A., Poel, B.V., Pieters, L., Berghe, D.V., Vlietinck, A., Kambu, K., Tona, L. 1995. In vitro anticomplementary activity of constituents from Morinda morindoides. Journal of Natural Products 8(3): 372-378.

Imakura, Y., Kobayashi, S., Mima, A. 1985. Bitter phenyl propanoid glycosides from Campsis chinensis. Phytochemistry 24(1): 139-146.

Jung, K.Y., Oh, S.R., Park, S.H., Lee, I.S., Ahn, K.S., Lee, J.J., Lee, H.K. 1998. Anti-complement activity of tiliroside from the flower buds of Magnolia fargesii. Biological \& Pharmaceutical Bulletin 21(10): 1077-1078.

Kim, T.W. 1994. The Woody Plants of Korea. Kyohak Press: Seoul, Korea. pp.58-59.

Li, G., Xu, M.L., Choi, H.G. L, S.H., Jahng, Y.D., Lee, C.S., Moon, D.C., Woo, M.H., Son, J.K. 2003. Four new diarylheptanoids from the roots of Juglans mandshurica. Chemical \& Pharmaceutical Bulletin 51(3): 262-264.

Min, B.S., Nakamura, N., Miyashiro, H., Kim, Y.H., Hattori, M. 2000. Inhibition of human immunodeficiency virus type 1 reverse transcriptase and ribonuclease $\mathrm{H}$ activities by constituents of Juglans mandshurica. Chemical \& Pharmaceutical Bulletin 48(2): 194-200.

Min, B.S., Lee, S.Y., Kim, J.H., Lee, J.K., Kim, T.J., Kim, D.H., Kim, Y.H., Joung, H., Lee, H.K., Nakamura, N., Miyashiro, H., Hattori, M. 2003. Anti-complement activity of constituents from the stem-bark of Juglans mandshurica. Biological \&
Pharmaceutical Bulletin 26(7): 1042-1044.

Oh, S.R., Kinjo, J., Shii, Y., Ikeda, T., Ahn, K.S., Kim, J.H., Lee, H.K. 2000. Effects of triterpenoids from Pueraria lobata on immunohemolysis: $\beta$-Dglucuronic acid plays an active role in anticomplementary activity in vitro. Planta Medica 66(6): 506-510.

Park, S.H., Oh, S.R., Jung, K.Y., Lee, I.S., Ahn, K.S., Kim, J.H., Kim, Y.S., Lee, J.J., Lee, H.K. 1999. Acylated flavonol glycosides with anti-complement activity from Persicaria lapathifolia. Chemical \& Pharmaceutical Bulletin 47(10): 1484-14686.

Park, S., Kim, N., Yoo, G.J., Kim, S.N., Kwon, H.J., Jung, K.W., Oh, D.C., Lee, Y.H., Kim, S.H. 2017. Phenolics and neolignans isolated from the fruits of Juglans mandshurica Maxim. and their effects on lipolysis in adipocytes. Phytochemistry 137(8): $87-93$.

Seikel, M.K., Hillis, W.E. 1970. Hydrolysable tannins of Eucalyptus delegatensis wood. Phytochemistry 9(5): 1115-1128.

Si, C.L., Gao, Y., Wu, L., Liu, R., Wang, G.H., Dai, L., Li, X.H., Hong, Y.M. 2017. Isolation and characterization of triterpenoids from the stem barks of Pinus massoniana. Holzforschung 71(9): 697-703.

Tanaka, T., Tachibana, H., Nonaka, G., Nishioka, I., Hsu, F.L., Kohda, H., Tanaka, O. 1993. Tannins and related compounds. CXXII. New dimeric, trimeric and tetrameric ellagitannins, lambertianins A-D, from Rubus lambertianus Seringe. Chemical \& Pharmaceutical Bulletin 41(7): 1214-1220.

Tsujita, T., Matsuo, Y., Saito, Y., Tanaka, T. 2017. Enzymatic oxidation of ellagitannin and a new ellagitannin metabolite from Camellia japonica leaves. Tetrahedron 73(5): 500-507.

Wang, T.M., Liu, J., Yi, T., Zhai, Y.J. Zhang, H., Chen, H.B., Cai, S.Q., Kang, T.G., Zhao, Z.Z. 2017. 
Zi-Jiang Li $\cdot$ Shilin Chen $\cdot$ Xiang-Hao Yang $\cdot$ Rui Wang $\cdot$ Hee-Jeong Min $\cdot$ Lei Wu $\cdot$ Chuan-Ling Si $\cdot$ Young-Soo Bae

Multiconstituent identification in root, branch, and leaf extracts of Juglans mandshurica using ultra high performance liquid chromatography with quadrupole time-of-flight mass spectrometry. Journal of Separation Science 40(17): 3340-3452.
Yamada, H., Ohtani, K., Kiyohara, H., Cyong, J.C., Otsuka, Y., Ueno, Y., Omura, S. 1985. Purification and chemical properties of anti-complementary polysaccharide from the leaves of Artemisia princeps. Planta Medica 51(2): 121-125. 